\title{
Prolonged 2-Day Esophageal pH-Metry with Impedance Monitoring Improves Symptom-Reflux Association Analysis
}

\author{
Agnieszka Swidnicka-Siergiejko • Andrzej Dabrowski
}

Received: 15 January 2013/ Accepted: 27 March 2013/Published online: 16 April 2013

(C) The Author(s) 2013. This article is published with open access at Springerlink.com

\begin{abstract}
Background The day-to-day variability in the number of reflux episodes and symptoms of gastro-esophageal reflux disease is high; therefore, the assessment of reflux disease based on 24-h monitoring may be inaccurate.

Aims The aim of the study was to compare prolonged (48 h) and standard (24 h) pH-impedance monitoring ( $\mathrm{pH}$ MII).

Methods Fifty-four consecutive patients with typical and atypical reflux symptoms underwent 48-h pH-MII. Acid exposure time (AET), total number of reflux episodes (TR), number of symptoms, and symptom association probability (SAP) were analyzed after the first $24 \mathrm{~h}$ and compared with the results obtained during $48 \mathrm{~h}$ of monitoring.

Results The differences between the fractions of patients with normal and abnormal total AET and TR on both days were not significant. The percentage of patients with positive SAP was $57.9 \%$ at $24 \mathrm{~h}$ and $71.9 \%$ at $48 \mathrm{~h}$ (difference: $14.81 \%, 95 \%$ CI $0.7-21.29, P<0.05)$. There were ten patients $(10 / 54,18.5 \%)$ with positive SAP after $48 \mathrm{~h}$ that had been negative in the first $24 \mathrm{~h}$. In comparison to $24 \mathrm{~h}$ monitoring, patients reported a significantly increased number of various symptoms correlated with reflux after $48 \mathrm{~h}$.

Conclusions Extending $\mathrm{pH}-\mathrm{MII}$ monitoring to $48 \mathrm{~h}$ does not improve the detection of abnormal acid exposure.
\end{abstract}

A. Swidnicka-Siergiejko ( $\square) \cdot$ A. Dabrowski

Department of Gastroenterology and Internal Medicine, Medical

University of Bialystok, ul. M. Curie-Sklodowskiej 24a, 15-276

Bialystok, Poland

e-mail: agnkatswidnicka@op.pl

A. Dabrowski

e-mail: adabrowski@umwb.edu.pl
However, it does increase the fraction of patients with positive symptom-reflux association by as much as $18.5 \%$.

Keywords Esophageal pH monitoring - Gastroesophageal reflux $\cdot$ Impedance $\cdot$ Symptom assessment

\section{Introduction}

Reflux monitoring with esophageal 24-h pH-metry has traditionally been based on measuring the abnormal esophageal acid exposure time (AET) and the number of acid reflux episodes [1]. However, the sensitivity of the $\mathrm{pH}$ test is limited by the day-to-day variability in AET. Up to $16 \%$ of patients with a positive $24-\mathrm{h} \mathrm{pH}$ monitoring had negative results on the follow-up 24-h pH-metry [2]. Moreover, up to $25 \%$ of subjects with erosive esophagitis have a false negative $\mathrm{pH}$-metry result, and the number of negative $\mathrm{pH}$ tests may be even higher in patients with nonerosive reflux disease (NERD) [3]. The false negative 24-h pH-metry may be a consequence of changes in daily activities and food consumption during a $\mathrm{pH}$ test, resulting in detecting a lower number of acid reflux episodes and symptoms. In some patients, these changes may be due to a poor tolerance to the trans-nasal placement of the $\mathrm{pH}$ catheter [4, 5]. These limitations have been overcome by the development of a wireless esophageal $\mathrm{pH}$ test that also allows for prolonged $\mathrm{pH}$ recording. Extending the monitoring period from 24 to $48 \mathrm{~h}$ increases the sensitivity of the $\mathrm{pH}$ test by 10-26\%, thereby improving symptom analysis as an increased number of symptoms is reported by patients with a longer duration of recording. Although the wireless system is generally well tolerated, the disadvantages include: chest discomfort, premature detachment, necessity of using endoscopy, and poor availability [6-9]. 
Additionally, the potential limitations of pH-tests are: (1) low sensitivity in detecting reflux with $\mathrm{pH}$ above 4.0 and (2) lack of the assessment of correlation of symptoms with non-acid reflux episodes.

Combined $\mathrm{pH}$ with impedance monitoring is the only available method with the ability to quantify acid and nonacid reflux, which increases the diagnostic yield of gastroesophageal reflux disease (GERD) by 15-20\% [10-13]. Compared to $\mathrm{pH}$-metry-only evaluation, the greatest asset of $\mathrm{pH}$-impedance monitoring is the possibility to assess those patients with persistent symptoms despite proton pump inhibitor (PPI) therapy [12-17]. pH-impedance is also helpful in evaluating patients with NERD and extraesophageal reflux symptoms [13, 16, 18-21]. Both groups represent the most problematic patients in clinical practice.

Taking into consideration the day-to-day variability in reflux and symptoms, and the occurrence of non-acid reflux, the 24 - or 48 -h $\mathrm{pH}$-only monitoring can be inaccurate in assessing some patients with refractory symptoms despite PPI therapy or NERD patients with extraesophageal reflux symptoms. Therefore, the aim of our study was to compare the prolonged $(48 \mathrm{~h}) \mathrm{pH}$ and impedance monitoring (pH-MII) with a standard 24-h test.

\section{Methods}

\section{Patients}

We performed a retrospective analysis of prolonged $\mathrm{pH}$ and impedance tests that were conducted in 57 consecutive patients. The patients were referred to the Department of Gastroenterology and Internal Medicine at the Medical University of Bialystok for $\mathrm{pH}$-impedance monitoring due to persistent GERD symptoms despite PPI therapy, and for the evaluation of extraesophageal GERD symptoms. The patients reported typical (heartburn, regurgitation) and atypical (chest pain, abdominal pain, belching, cough) reflux symptoms. In patients exhibiting persistent symptoms despite PPI treatment for a period of at least 2 months (with previously documented GERD: typical reflux syndrome, and/or esophagitis, and/or abnormal acid exposure off PPI therapy), pH-MII monitoring was performed on the continued twice daily standard dose of PPI therapy. In patients who were referred for the evaluation of potential association of extraesophageal reflux symptoms with GERD, to exclude or to confirm GERD as a cause of symptoms, pH-MII monitoring was performed off PPI therapy. Other causes of extraesophageal symptoms were excluded by cardiologists, allergologists, and laryngologists before referral. Exclusion criteria included a history of previous gastric or esophageal surgery, and esophageal motility disorders. Upper gastrointestinal endoscopy was performed in all patients within the last 12 months or before $\mathrm{pH}-\mathrm{MII}$ monitoring. Both the study protocol and all the procedures were approved by the Local Ethics Committee of the Medical University in Bialystok, and all the subjects gave their informed written consent before the start of any procedure.

\section{pH-Impedance Monitoring}

pH-MII monitoring was performed after an overnight fast using a Sleuth multi-channel intraluminal impedance system (Sandhill Scientific Inc., Highland Ranch, CO), consisting of a portable data logger and a catheter with one $\mathrm{pH}$ electrode and eight impedance electrodes at $3,5,7,9,15$, and $17 \mathrm{~cm}$ from the tip, positioned $5 \mathrm{~cm}$ above the upper border of the lower esophageal sphincter (LES) as determined by manometry. The patients were instructed to press the event marker button on the data logger whenever they experienced a symptom and to fill out a diary indicating the time of the symptom, the start and end times of their meals, changes in body position (recumbent, upright), and time of PPI intake. The patients were asked to consume at least three meals during the day and encouraged to try to maintain their normal daily routine. Meal periods were excluded from analysis. All data was collected on $256 \mathrm{MB}$ compact flash cards. After $48 \mathrm{~h}$ of monitoring (the time of monitoring included two nights), the data was downloaded onto a computer and analyzed using a semi-automated software system (BioView, Sandhill Scientific) and verified manually.

\section{Data Analysis}

The following data was analyzed: acid exposure time (AET), acid clearance time (ACT), bolus clearance time (BCT), number of reflux episodes (TR), number of reflux episodes reaching $15 \mathrm{~cm}$ above LES (proximal reflux), and the number of symptoms. Total acid exposure time (\% total time at $\mathrm{pH}$ below 4.0) of less than $4.2 \%$ over $24 \mathrm{~h}$ was considered normal for patients off PPI therapy, while less than $1.3 \%$ was considered a norm for patients on PPI therapy, in accordance with previously published criteria [22, 23]. Reflux episodes were classified as acid, weakly acidic, or weakly alkaline in accordance with previously reported criteria: (1) acid reflux: impedance-detected reflux with nadir $\mathrm{pH}$ below 4; (2) weakly acidic reflux: reflux with nadir $\mathrm{pH}$ between 4 and 7; (3) weakly alkaline reflux: reflux with nadir $\mathrm{pH}$ above 7 .

The number of symptoms related to acid reflux and weakly acidic reflux, as well as weakly alkaline reflux was calculated. Symptom-reflux association was performed using SI (symptom index) and SAP (symptom association probability) indexes for each patient. Separate analysis was performed for each individual symptom if the patient 
recorded symptoms of different types. The patient was considered as a patient with positive symptom-reflux association if he/she had at least one type of symptom correlated with reflux. For each patient, the number of different types of symptoms with positive reflux association was calculated. The SI and SAP were calculated according to the formula described by other authors [24, 25]. The SI was defined as the percentage of reflux-related symptoms preceded by reflux (with 2-min time window). The SAP was calculated by dividing the data set into consecutive 2 -min periods. We investigated whether reflux episodes occurred in each 2-min segment and in the 2-min period before each symptom. SAP indicates the statistical probability that the observed symptom-reflux association could have occurred by chance. The cutoff value for a positive SAP test was SAP $\geq 95 \%$ and for the SI test $\geq 50 \%$.

All parameters were analyzed separately for the first and second $24 \mathrm{~h}$ of monitoring (day 1 and day 2). Data measured during the first $24 \mathrm{~h}$ were compared to the final outcome after $48 \mathrm{~h}$ of monitoring (day $1+2$ ). All analyses were performed on all the patients participating in the study and, additionally, on two subgroups of patients: off PPI therapy and on PPI therapy.

At the end of the $\mathrm{pH}$-impedance test, all patients were asked to answer the following three questions: "Did you tolerate the study well?", "Did you experience any side effects associated with the probe?", and "Would you do the test again?".

\section{Statistical Analysis}

Not-normally distributed data obtained from the subjects were summarized by median values and interquartile ranges (IQRs) and comparisons between them on day 1 and day 2 were performed using the Wilcoxon matched-pairs signed-rank test. The differences between the fractions of patients (expressed as a percentage with a $95 \%$ confidence interval $[\mathrm{CI}]$ ) with positive and negative SI and SAP, normal and abnormal AET, and normal and abnormal total number of reflux episodes in each period of the study time were performed using the McNemar exact testing. Differences were considered statistically significant when $P<0.05$. All statistical analyses were performed using STATA statistical software.

\section{Results}

Patients and Technical Success of 48-h pH-MII Monitoring

Fifty-seven patients (median age 49, 20-72 years, 32 females) agreed to undergo $\mathrm{pH}$ and impedance monitoring for $48 \mathrm{~h}$. One patient did not complete the two-day-long study due to the failure of the monitoring device battery. One patient was excluded from analysis due to a technical problem with the $\mathrm{pH}$ electrode. In one patient, the probe was disconnected from the Sleuth device at night. Therefore, complete two-day-long recordings were available for 54 patients $(94.7 \%)$.

In 33 patients, pH-MII monitoring was performed off PPI therapy. Endoscopy showed erosive esophagitis in eight of those patients $(8 / 33 ; 24.2 \%$; grade $\mathrm{A}$ in six patients and grade B in two patients according to Los Angeles classification), ESEM (endoscopically suspected esophageal metaplasia) in one patient $(1 / 33 ; 3 \%)$, and hiatal hernia in five patients $(5 / 33 ; 15.2 \%)$.

In 21 patients with previously diagnosed GERD and refractory reflux symptoms, $\mathrm{pH}$ and impedance monitoring were performed on PPI therapy. Among those 21 patients without erosive esophagitis, four patients $(4 / 21 ; 19 \%)$ had hiatal hernia.

pH-MII monitoring was well tolerated by all subjects with the exception of eight patients $(8 / 54 ; 14.8 \%)$ : three patients had throat pain (two on day 1 and one on day 2) and five experienced nasal discomfort during monitoring (two on day 1 and three on day 2). Importantly, $76 \%$ of the patients would do the test again. The median duration of recording was $45.82 \mathrm{~h}$ (IQR 45.13-47.09).

\section{Reflux Episodes}

The characteristics of reflux episodes are presented in Table 1. Compared with reflux episodes on day 1, reflux episodes on day 2 had similar characteristics except for the median number of acidic reflux episodes, which occurred more frequently on day 1 . This difference was detectable in patients on PPI therapy, but not in patients who were offtherapy (data not shown). The abnormal total number of reflux episodes on both day 1 and day 2 was reported by $29.6 \%(16 / 54)$ of patients. Furthermore, $64.8 \%(35 / 54)$ had normal total number of reflux episodes on both days of monitoring. There were no significant differences between the fractions of patients with abnormal and normal number of reflux episodes documented on day 1 and day $2(1.85 \%$; $95 \% \mathrm{CI}-4.51$ to $5.46 ; P=1.000$; Fig. 1 ).

Esophageal Acid Exposure Time, Acid Clearance Time, and Bolus Clearance Time

The median total AET, ACT, and BCT on day 1 were similar to day 2 in all patients (Table 2). Overall, $81.5 \%$ (44/54) of patients had similar AET on both days 1 and 2. There was no concordance of AET measurement between both days in $18.5 \%(10 / 54)$ of patients (Fig. 1). There were no significant differences between the fractions of 
Table 1 Characteristics of reflux episodes

\begin{tabular}{lllll}
\hline The study group $(n=54)$ & $\begin{array}{l}\text { Day 1, } \\
\text { median }(25-75 \%)\end{array}$ & $\begin{array}{l}\text { Day 2, } \\
\text { median (25-75 \%) }\end{array}$ & $\begin{array}{l}\text { Day 1 and day 2, } \\
\text { median }(25-75 \%)\end{array}$ \\
\hline Total reflux episodes & $48(36-73)$ & $48(34-67)$ & 0.1231 & $97(73-138)$ \\
Acidic reflux & $24(14-42)$ & $21.5(11-39)$ & 0.0280 & $44.5(27-79)$ \\
Weakly acidic reflux & $17.5(12-31)$ & $17(12-37)$ & 0.2244 & $33(25-53)$ \\
Weakly alkaline reflux & $0(0-1)$ & $0(0-2)$ & 0.4799 & $1(0-3)$ \\
Proximal reflux & $22(14-41)$ & $23.5(16-36)$ & 0.8767 & $42(27-75)$ \\
\hline
\end{tabular}

Fig. 1 Day-to-day distribution of abnormal and normal total acid exposure time and total reflux episodes. $n$ number of patients
Acid exposure time

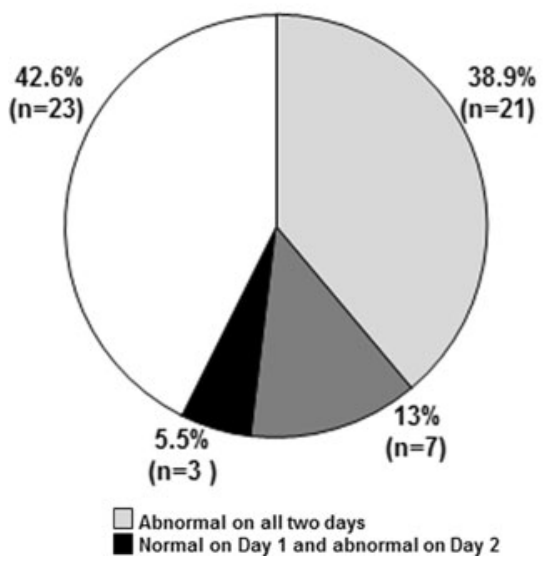

Total reflux episodes

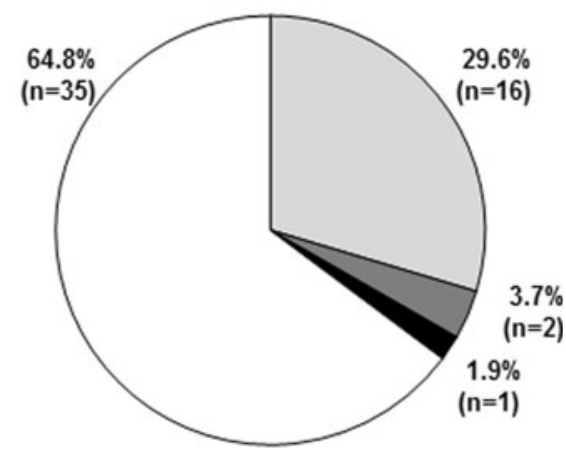

Abnormal on Day 1 and normal on Day 2 Normal on all two days patients with normal and abnormal total AET documented on day 1 and day $2(7.41 \% ; 95 \%$ CI -5.65 to $16.05 \%$; $P=0.3438)$.

\section{Symptoms Reported by Patients}

There were only two patients who did not report symptoms during the first day, but had symptoms during the second day of monitoring. One patient with symptoms on day $1 \mathrm{did}$ not report symptoms on day 2. Overall, a median number of 11 (IQR 6-26), 9.5 (IQR 5-32), and 21 (IQR 10-58) symptoms per patient was reported during day 1 , day 2 , and after 2 days of monitoring, respectively. The following symptoms were reported by the patients: heartburn (37\%; 20/54), regurgitation $(48 \% ; 26 / 54)$, abdominal pain $(46.3 \%, 25 / 54)$, chest pain $(42.6 \%, 23 / 54)$, and belching (59\%; 32/54).

\section{Symptom-Reflux Association in All Patients}

When symptom-reflux association was analyzed separately for the first and second 24-h period of monitoring, a significant difference was found in the number of patients with positive SI [day 1: $68.5 \%,(37 / 54)$ vs. day 2: $81.5 \%$ (44/54), difference: 12.96; $95 \%$ CI $0.58-16.57$; $P=0.0391]$. There was no difference between day 1 and day 2 in the percentage of patients with positive SAP [day
1: $59.2 \%,(32 / 54)$ vs. day 2: $63 \%,(34 / 54)$, difference: $3.7 \%$; $95 \%$ CI -12.83 to $18.98 ; P=0.8145$ ] (Fig. 2).

However, we found significant differences in the number of patients with positive SI or SAP on the first day and after 2 days of monitoring. The percentage of patients with positive SI was $68.5 \%(37 / 54)$ on day 1 and $87.0 \%$ (47/ 54 ) on days $1+2$ (difference: $18.52 \%$; $95 \%$ CI 2.58-27.23; $P=0.0213)$. The percentage of patients with positive SAP was $59.2 \%(32 / 54)$ on day 1 and $74.1 \%(40 /$ 54 ) on days $1+2$ (difference: $14.81 \%, 95 \%$ CI 0.7-21.29; $P=0.0386$; Fig. 3).

Symptom-Reflux Association in Subgroups of Patients Off and On PPI Therapy

No significant differences in the number of patients with positive SI or SAP during the first $24 \mathrm{~h}$ and following 2 days of recording were found in patients on PPI therapy upon analyzing the symptom-reflux association separately in both the off- and on-PPI therapy subgroups of patients. The percentage of patients tested on PPI therapy with positive SI was $71.4 \%(15 / 21)$ on day 1 and $81.0 \%(17 /$ 21 ) on days $1+2$ (difference: $9.52 \%, 95 \% \mathrm{CI}-11.65$ to $18.81, P=0.6250)$. The percentage of patients tested on PPI therapy with positive SAP was $66.7 \%$ (14/21) on day 1 and $72.6 \%(16 / 21)$ on days $1+2$ (difference: $9.52 \%$, $95 \% \mathrm{CI}-11.65$ to $18.81, P=0.6250)$. However, the 
Table 2 pH-MII parameters in relation to the duration of analysis and treatment with proton pump inhibitor

\begin{tabular}{|c|c|c|c|}
\hline The study group $(n=54)$ & $\begin{array}{l}\text { Day } 1 \text {, } \\
\text { median }(25-75 \%)\end{array}$ & $\begin{array}{l}\text { Day } 2 \text {, } \\
\text { median }(25-75 \%)\end{array}$ & $P$ \\
\hline \multicolumn{4}{|l|}{ Duration of analysis (s) } \\
\hline Total & $22(21.2-22.52)$ & $22.03(21.02-22.36)$ & 0.6620 \\
\hline Upright & $12.04(10.28-13.24)$ & $12.17(10.51-13.11)$ & 0.8341 \\
\hline Recumbent & $9.39(8.53-10.81)$ & $9.52(8.46-11.29)$ & 0.9709 \\
\hline AET total $(\%)$ & $2.45(0.7-5.3)$ & $1.9(0.6-4.4)$ & 0.0974 \\
\hline ACT total (sec) & $89.5(38.0-161.0)$ & $88.0(46.0-130.0)$ & 0.1201 \\
\hline BCT total (sec) & $11.05(9.0-15.0)$ & $11.0(8.0-13.0)$ & 0.7505 \\
\hline \multicolumn{4}{|l|}{ On PPI $(n=21)$} \\
\hline AET total $(\%)$ & $0.6(0.0-2.1)$ & $0.4(0.1-0.8)$ & 0.0677 \\
\hline ACT total (sec) & $68.0(24.0-92.0)$ & $50.0(37.0-93.0)$ & 0.8077 \\
\hline BCT total (sec) & $10.0(7.0-15.0)$ & $11.0(8.0-13.0)$ & 0.3103 \\
\hline \multicolumn{4}{|l|}{ Off PPI $(n=33)$} \\
\hline AET total $(\%)$ & $4.5(1.4-7.6)$ & $3.7(2.0-6.0)$ & 0.3301 \\
\hline ACT total $(\%)$ & $132.0(52.0-204.0)$ & $95.0(68.0-173.0)$ & 0.2640 \\
\hline BCT total $(\%)$ & $12.0(10.0-15.0)$ & $12.0(9.0-13.0)$ & 0.3895 \\
\hline
\end{tabular}

$A E T$ acid exposure time, $A C T$ acid clearance time, $B C T$ bolus clearance time, $P P I$ proton pump inhibitor

Fig. 2 Symptom-reflux association in relation to the duration of $\mathrm{pH}-\mathrm{MII}$ monitoring. SI symptom index, SI positive $\geq 50 \%$, SI negative $<50 \%$. SAP symptom association probability, SAP positive $\geq 95 \%$, SAP negative $<95 \%$
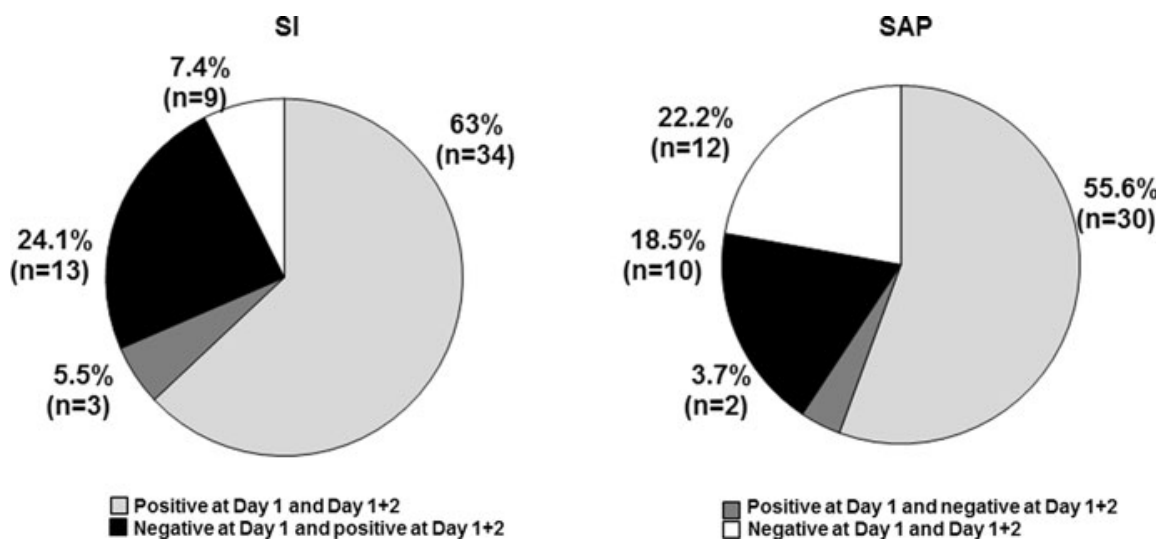

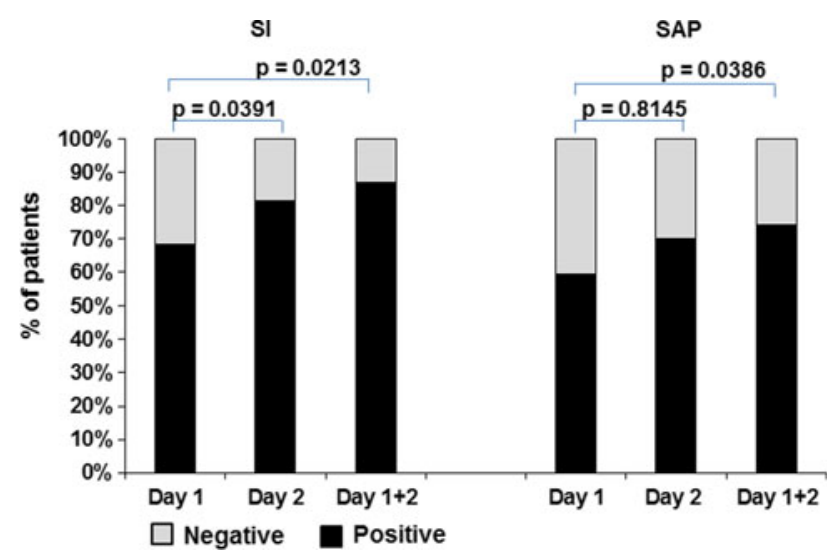

Fig. 3 Day-to-day distribution of positive and negative symptomreflux association: symptom index and symptom association probability. $n$ number of patients, $S I$ symptom index, SI positive $\geq 50 \%$. $S A P$ symptom association probability, SAP positive $\geq 95 \%$ difference in the percentage of patients with positive SI on day 1 and days $1+2$ was significant in patients off PPI therapy [24.4\%, day 1: $66.7 \%(22 / 33)$ vs. days $1+2$ : $90.9 \%$ (30/33), $95 \%$ CI $1.15-34.85, P=0.0386]$. The difference in the percentage of patients tested off PPI therapy with positive SAP on day 1 and days $1+2$ was not significant [18.18\%, day 1: $54.5 \%$ (18/33) vs. days $1+2: \quad 72.7 \%(24 / 33), 95 \%$ CI -1.29 to 24.09 , $P=0.0703]$.

Characteristics of Patients with Negative SI or SAP on Day 1 and Positive SI or SAP on Days $1+2$

Out of the total number of patients, $13(24.1 \%)$ subjects were found to have a negative SI on the first day of assessment followed by a positive SI after 2 days of monitoring. Only three of those 13 subjects were patients 
with refractory GERD symptoms tested on PPI therapy. Among all the patients, ten individuals (18.5\%) had a negative SAP on day 1 and a positive SAP after 2 days of monitoring (Fig. 3). All patients with positive SAP also had positive SI. Seven of those $10(70 \%)$ subjects were patients off-PPI therapy and all had normal endoscopy findings. Five of the above-mentioned seven patients had abnormal acid exposure time and positive SAP for typical symptoms in only one case, for both typical and atypical symptoms (chest pain, cough, belching) in two cases, and for atypical symptoms (cough, chest pain) in only two patients. These patients were diagnosed as having NERD.

Two of the ten patients with positive SAP had symptoms correlated with acidic reflux alone, three patients had symptoms correlated with acidic and weakly acidic reflux, and five patients with weakly acidic reflux alone.

\section{Association of Symptoms of Different Types} with Reflux

In comparison to the one-day assessment, patients reported a significantly increased number of various symptoms correlated with reflux episodes (positive SAP) following 2 days of monitoring (Fig. 4).

\section{Discussion}

To the best of our knowledge, our study was the first to demonstrate the potential of esophageal $\mathrm{pH}$ with impedance monitoring recorded over a period of $48 \mathrm{~h}$.

The sensitivity of catheter-based 24-h pH-metry is limited by the day-to-day variability in AET, number of reflux episodes, and the number of symptoms reported by the patients [26]. It has been suggested that $\mathrm{pH}$ monitoring using a wireless capsule generates less adverse symptoms than the traditional catheter-based system [7-9, 27].

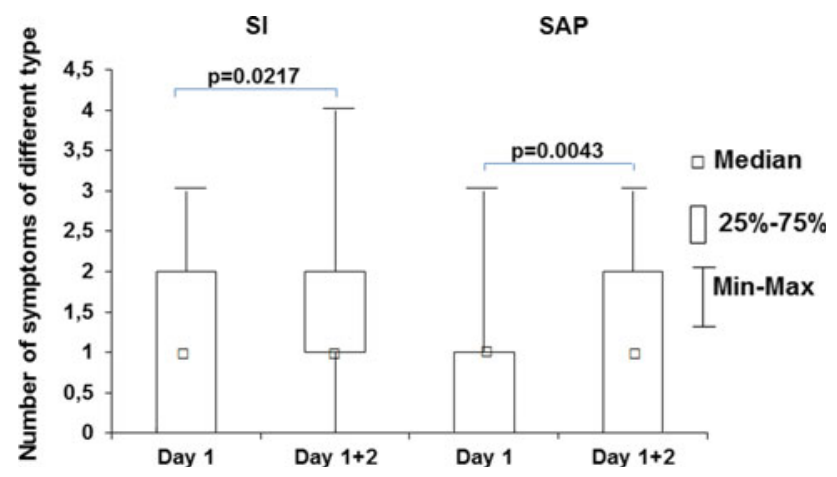

Fig. 4 The number of symptoms of different type with positive symptom-reflux association in subgroups of patients off proton pump inhibitor therapy. SI symptom index, SAP symptom association probability
However, 10-40 \% of patients investigated with a capsulebased protocol experienced symptoms including chest discomfort or foreign body sensation and up to $4 \%$ of them may require endoscopic removal of the capsule due to severe chest pain. Additionally, endoscopy needs to be performed to ensure the proper placement in the esophagus and to assess the gastro-esophageal junction [7, 28-31]. Although a catheter-based study is not well tolerated in up to $10 \%$ of the patients and may affect activity, endoscopy is not necessary. Furthermore, compared to the catheterbased system, the wireless capsule is less available. Our study showed that prolonging monitoring using $\mathrm{pH}-\mathrm{MII}$ is generally well tolerated. Minor adverse symptoms such as throat pain and nasal discomfort were reported by $14.8 \%$ of the patients. However, $76 \%$ of all patients stated that they would undergo the test again.

Extending $\mathrm{pH}$ monitoring to $48 \mathrm{~h}$ by using a wireless system improves the detection of abnormal AET by $22 \%$ and increases the sensitivity of the $\mathrm{pH}$ test [7, 8, 31, 32]. In comparison, $\mathrm{pH}-\mathrm{MII}$ monitoring allows for the identification of all acidic, weakly acidic, and weakly alkaline reflux, thereby increasing the diagnostic yield by 15-20\% [1013]. In our study, we did not demonstrate any significant differences between the 2 days of $\mathrm{pH}$-MII monitoring in the percentage of patients with normal and abnormal results of AET and reflux episode numbers.

An abnormal number of reflux episodes or increased AET do not automatically imply that reflux is the cause of the symptoms, and normal study does not exclude reflux as a cause of the symptoms. In clinical practice, the assessment of the association between reflux and symptoms is more important. There are limitations to the most common indices used for assessing the correlation [33]. SI is defined as the percentage of symptoms that are reflux related, regardless of the total number of reflux episodes. Therefore, patients with a lower number of symptoms have a higher probability of having positive SI. SAP was developed to overcome the limitations of SI [24, 25]. When a patient reports single, rare symptoms, it is difficult or even impossible to assess their correlation with reflux; even 24-h monitoring may not be sufficient. A prolonged wireless $\mathrm{pH}$ test improves the symptom-acid reflux correlation $[8,26$, 31]. Our study demonstrated that the number of various symptoms increased over time; therefore, indicating that the 2-day test makes the symptom-reflux association more useful. There were ten patients $(18.5 \%)$ with positive SAP and 13 patients $(24.1 \%)$ with positive SI after $48 \mathrm{~h}$ that had been negative in the first $24 \mathrm{~h}$. Such results were particularly evident in patients with atypical symptoms, in whom a pH-MII test was performed to confirm or exclude GERD as a cause of symptoms. We recognized NERD in five of seven patients tested off PPI therapy and with positive SAP only after 2 days of monitoring. In addition, 
four out of five of those patients had positive SAP for atypical symptoms. Additionally, two patients met the criteria for functional heartburn. Five out of ten patients with positive SAP after 2 days of monitoring had symptoms correlated with weakly acidic reflux alone, which would not be detected by $24-$ or $48-\mathrm{h}$ pH study.

Taking into consideration potentially decreased oral intake and physical activity during the catheter-based test, as well as day-to-day variations in reflux episodes and symptom numbers, prolonged monitoring may facilitate diagnosis in patients with a negative 24-h pH study. Sweis et al. [34] demonstrated that prolonged, wireless $\mathrm{pH}-$ monitoring increases test sensitivity and diagnostic yield in patients with continuing esophageal symptoms despite negative 24-h catheter $\mathrm{pH}$-studies and concluded that without a definitive diagnosis many would not have received effective treatment. In this study, a good outcome was reported by ten out of 12 patients who underwent antireflux surgery. Additionally, there is data demonstrating the clinical usefulness of prolonged wireless $\mathrm{pH}$ monitoring in off-PPI treatment evaluation [31, 35] and the pH-MII test for better characterization of patients with persistent symptoms despite PPI therapy [12-21, 36-38]. The utility of prolonged $\mathrm{pH}-\mathrm{MII}$ monitoring, including the period off and on PPI therapy, might be an issue worthy of future study.

Our study had a number of limitations. The time of monitoring among the individual patients differed slightly, although not significantly. All the patients that completed 2 days ( 2 nights) were included in the study; also, the minimum time of recording $(21 \mathrm{~h}$ for each scheduled $24 \mathrm{~h}$ period) was achieved. However, there are no standard values for the 48-h $\mathrm{pH}$-impedance monitoring, and the results of this study should be interpreted with caution. Moreover, clinical significance of weakly acidic reflux detected by $\mathrm{pH}$-impedance test remains an area of controversy. Most importantly, we should also take into consideration that increasing the diagnostic yield of the study may also increase false positives. Positive predictive values may likely decrease with additional testing and may best serve to exclude GERD [33]. Future studies should also evaluate whether making symptom-reflux correlation analysis more efficient can influence the effects of therapy.

In summary, our study demonstrated that prolonged 48-h pH-MII monitoring is possible and generally well tolerated. Extending pH-MII monitoring to 2 days does not improve the detection of abnormal acid exposure. However, it does increase the reported number of various symptoms with positive reflux association and the fraction of patients with positive SAP by as much as $18.5 \%$. It may be considered in patients with normal endoscopy who report rare or atypical symptoms in order to exclude or confirm GERD as a causative factor. A direct comparison of prolonged 48-h $\mathrm{pH}$-impedance with wireless $48-\mathrm{h} \mathrm{pH}$ monitoring, that takes into account all their advantages and disadvantages, should constitute the subject of future studies.

\section{Conflict of interest None.}

Open Access This article is distributed under the terms of the Creative Commons Attribution Noncommercial License which permits any noncommercial use, distribution, and reproduction in any medium, provided the original author(s) and the source are credited. The exclusive right to any commercial use of the article is with Springer.

\section{References}

1. Jamieson JR, Stein HJ, DeMeester TR, et al. Ambulatory 24-h esophageal $\mathrm{pH}$ monitoring: normal values, optimal thresholds, specificity, sensitivity, and reproducibility. Am J Gastroenterol. 1992;87:1102-1111.

2. Wiener GJ, Morgan TM, Copper JB, et al. Ambulatory 24-hour esophageal $\mathrm{pH}$ monitoring. Reproducibility and variability of $\mathrm{pH}$ parameters. Dig Dis Sci. 1988;3:1127-1133.

3. Martinez SD, Malagon IB, Garewal HS, Cui H, Fass R. Nonerosive reflux disease (NERD)-acid reflux and symptom patterns. Aliment Pharmacol Ther. 2003;17:537-545.

4. Mearin F, Balboa A, Dot J, Maldonado O, Malagelada JR. How standard is a standard day during a standard ambulatory 24-hour esophageal pH monitoring? Scand J Gastroenterol. 1998;33:583-585.

5. Fass R, Hell R, Sampliner RE, et al. Effect of ambulatory 24-hour esophageal pH monitoring on reflux-provoking activities. Dig Dis Sci. 1999;44:2263-2269.

6. Hirano I, Richter JE. Practice parameters committee of the American College of Gastroenterology. ACG practice guidelines: esophageal reflux testing. Am J Gastroenterol. 2007;102:668-685.

7. Pandolfino JE, Richter JE, Ours T, Guardino JM, Chapman J, Kahrilas PJ. Ambulatory esophageal $\mathrm{pH}$ monitoring using a wireless system. Am J Gastroenterol. 2003;98:740-749.

8. Prakash C, Clouse RE. Value of extended recording time with wireless $\mathrm{pH}$ monitoring in evaluating gastroesophageal reflux disease. Clin Gastroenterol Hepatol. 2005;3:329-334.

9. Sweis R, Fox M, Anggiansah R, et al. Patient acceptance and clinical impact of Bravo monitoring in patients with previous failed catheter-based studies. Aliment Pharmacol Ther. 2009;29: 669-676.

10. Sifrim D, Castell D, Dent J, Kahrilas PJ. Gastro-oesophageal reflux monitoring: review and consensus report on detection and definitions of acid, non-acid, and gas reflux. Gut. 2004;531024-1031.

11. Bredenoord AJ, Weusten BL, Timmer R, et al. Addition of esophageal impedance monitoring to $\mathrm{pH}$ monitoring increases the yield of symptom association analysis in patients off PPI therapy. Am J Gastroenterol. 2006;101:453-459.

12. Zerbib F, Roman S, Ropert A, et al. Esophageal pH-impedance monitoring and symptom analysis in GERD: a study in patients off and on therapy. Am J Gastroenterol. 2006;101:1956-1963.

13. Blondeau K, Tack J. Pro: impedance testing is useful in the management of GERD. Am J Gastroenterol. 2009;104:2664-2666.

14. Mainie I, Tutuian R, Shay S, et al. Acid and non-acid reflux in patients with persistent symptoms despite acid suppressive therapy: a multicentre study using combined ambulatory impedancepH monitoring. Gut. 2006;55:1398-1402. 
15. Hemmink GJ, Bredenoord AJ, Weusten BL, Monkelbaan JF, Timmer R, Smout AJ. Esophageal $\mathrm{pH}$-impedance monitoring in patients with therapy-resistant reflux symptoms: 'on' or 'off' proton pump inhibitor? Am J Gastroenterol. 2008;103:2446-2453.

16. Sifrim D, Zerbib F. Diagnosis and management of patients with reflux symptoms refractory to proton pump inhibitors. Gut. 2012; 61:1340-1354.

17. Pritchett JM, Aslam M, Slaughter JC, Ness RM, Garrett CG, Vaezi MF. Efficacy of esophageal impedance/pH monitoring in patients with refractory gastroesophageal reflux disease, on and off therapy. Clin Gastroenterol Hepatol. 2009;7:743-748.

18. Savarino E, Zentilin $P$, Tutuian $R$, et al. The role of nonacid reflux in NERD: lessons learned from impedance-pH monitoring in 150 patients off therapy. Am J Gastroenterol. 2008;103:2685-2693.

19. Sifrim D, Dupont L, Blondeau K, Zhang X, Tack J, Janssens J. Weakly acidic reflux in patients with chronic unexplained cough during 24 hour pressure, $\mathrm{pH}$, and impedance monitoring. Gut. 2005;54:449-454.

20. Blondeau K, Dupont LJ, Mertens V, Tack J, Sifrim D. Improved diagnosis of gastro-oesophageal reflux in patients with unexplained chronic cough. Aliment Pharmacol Ther. 2007;25:723-732.

21. Malhotra A, Freston JW, Aziz K. Use of $\mathrm{pH}$-impedance testing to evaluate patients with suspected extraesophageal manifestations of gastroesophageal reflux disease. J Clin Gastroenterol. 2008; 42:271-278.

22. Shay S, Tutuian R, Sifrim D, et al. Twenty-four hour ambulatory simultaneous impedance and $\mathrm{pH}$ monitoring: a multicenter report of normal values from 60 healthy volunteers. Am J Gastroenterol. 2004:99:1037-1043.

23. Tutuain R, Mainie I, Agrawal A, Freeman J, Castel DO. Normal values for ambulatory 24-hour combined impedance-pH monitoring on acid suppressive therapy [abstract]. Gastroenterology. 2006;130:A171.

24. Wiener GJ, Richter JE, Copper JB, Wu WC, Castell DO. The symptom index: a clinically important parameter of ambulatory 24-hour esophageal pH monitoring. Am J Gastroenterol. 1988;83: 358-361.

25. Weusten BL, Roelofs JM, Akkermans LM, Van Berge-Henegouwen GP, Smout AJ. The symptom-association probability: an improved method for symptom analysis of 24-hour esophageal pH data. Gastroenterology. 1994;107:1741-1745.

26. Scarpulla G, Camilleri S, Galante P, Manganaro M, Fox M. The impact of prolonged $\mathrm{pH}$ measurements on the diagnosis of gastroesophageal reflux disease: 4-day wireless $\mathrm{pH}$ studies. Am J Gastroenterol. 2007;102:2642-2647.
27. Wenner J, Johnsson F, Johansson J, Oberg S. Wireless esophageal $\mathrm{pH}$ monitoring is better tolerated than the catheter-based technique: results from a randomized cross-over trial. Am J Gastroenterol. 2007;102:239-245.

28. Lee YC, Wang HP, Chiu HM, et al. Patients with functional heartburn are more likely to report retrosternal discomfort during wireless pH monitoring. Gastrointest Endosc. 2005;62:834-841.

29. Ahlawat SK, Novak DJ, Williams DC, Maher KA, Barton F, Benjamin SB. Day-to-day variability in acid reflux patterns using the BRAVO pH monitoring system. J Clin Gastroenterol. 2006; 40:20-24.

30. Remes-Troche JM, Ibarra-Palomino J, Carmona-Sánchez RI, Valdovinos MA. Performance, tolerability, and symptoms related to prolonged $\mathrm{pH}$ monitoring using the Bravo system in Mexico. Am J Gastroenterol. 2005;100:2382-2386.

31. Garrean CP, Zhang Q, Gonsalves N, Hirano I. Acid reflux detection and symptom-reflux association using 4-day wireless $\mathrm{pH}$ recording combining 48-hour periods off and on PPI therapy. Am J Gastroenterol. 2008;103:1631-1637.

32. Tseng D, Rizvi AZ, Fennerty MB, et al. Forty-eight-hour $\mathrm{pH}$ monitoring increases sensitivity in detecting abnormal esophageal acid exposure. J Gastrointest Surg. 2005;9:1043-1051.

33. Connor J, Richter J. Increasing yield also increases false positives and best serves to exclude GERD. Am J Gastroenterol. 2006;101:460-463.

34. Sweis R, Fox M, Anggiansah A, Wong T. Prolonged, wireless $\mathrm{pH}$-studies have a high diagnostic yield in patients with reflux symptoms and negative $24-\mathrm{h}$ catheter-based $\mathrm{pH}$-studies. Neurogastroenterol Motil. 2011;23:419-426.

35. Calabrese C, Liguori G, Gabusi V, et al. Ninety-six-hour wireless oesophageal $\mathrm{pH}$ monitoring following proton pump inhibitor administration in NERD patients. Aliment Pharmacol Ther. 2008; 28:250-255.

36. Sharma N, Agarwal A, Freeman J, Vela MF, Castell D. An analysis of persistent symptoms in acid-suppressed patients undergoing impedance-pH monitoring. Clin Gastroenterol Hepatol. 2008;6: 521-524.

37. Boeckxstaens GE, Smout A. Systematic review: role of acid, weakly acidic and weakly alkaline reflux in gastro-oesophageal reflux disease. Aliment Pharmacol Ther. 2010;32:334-343.

38. Becker V, Bajbouj M, Waller K, Schmid RM, Meining A. Clinical trial: persistent gastro-oesophageal reflux symptoms despite standard therapy with proton pump inhibitors - a followup study of intraluminal-impedance guided therapy. Aliment Pharmacol Ther. 2007;26:1355-1360. 